\title{
Acute Intestinal Invagination of the Child at the Teaching Hospital of Bouaké: Ultrasound Diagnosis and Clinical-Echo-Surgical Correlation
}

\author{
Bouassa Davy Melaine Kouakou ${ }^{1,2 *}$, Konaté Issa ${ }^{1,2}$, Kouamé Paul Bonfils Kouassi',2, \\ Adoubs Célestin Bénié2,3, Tsri Akoli Baudouin Bravo, ${ }^{1,2}$, Kesse Emile Tanoh ${ }^{1,2}$, \\ Allou Florent Kouadio, ${ }^{1,2}$, Brou Lambert Yao ${ }^{1,2}$, Achie Jean-Régis Akobe ${ }^{2,3}$, Sara Carole Sanogo1,2, \\ Malick Soro ${ }^{1,2}$, Kouadio N'Dri'1,2
}

${ }^{1}$ Medical Imaging and Radiodiagnostic Departement of the Teaching Hospital of Bouaké, Bouaké, Ivory Coast

${ }^{2}$ Training and Research Unit Medical Sciences Alassane Ouattara University, Bouaké, Ivory Coast

${ }^{3}$ Pediatric Surgery Unit of the Teaching hospital of Bouaké, Bouaké, Ivory Coast

Email: *bouassakdav@gmail.com

How to cite this paper: Kouakou, B.D.M., Issa, K., Kouassi, K.P.B., Bénié, A.C., Bravo, T.A.B., Tanoh, K.E., Kouadio, A.F., Yao, B.L., Akobe, A.J.-R., Sanogo, S.C., Soro, M. and N'Dri, K. (2021) Acute Intestinal Invagination of the Child at the Teaching Hospital of Bouaké: Ultrasound Diagnosis and Clinical-Echo-Surgical Correlation. Open Journal of Medical Imaging, 11, 18-28. https://doi.org/10.4236/ojmi.2021.111003

Received: December 3, 2020

Accepted: March 5, 2021

Published: March 8, 2021

Copyright $\odot 2021$ by author(s) and Scientific Research Publishing Inc. This work is licensed under the Creative Commons Attribution International License (CC BY 4.0).

http://creativecommons.org/licenses/by/4.0/

(c) $\underset{\mathrm{BY}}{\mathrm{i}}$ Open Access

\begin{abstract}
Background: Acute intestinal invagination or intussusception is the most common abdominal surgical emergency in infants, but it can occur at any age. Performing an ultrasound scan at the slightest clinical suspicion contributes to early diagnosis and therapeutic management. Objective: To show the relevance of ultrasound in the therapeutic management of the child's intussusception through a correlation between the ultrasound diagnosis and the clinical and/or per operative diagnosis. Patients and Methods: It was a retrospective study of 24 cases from July 2017 to September 2020 (30 months) in the Medical Imaging and Paediatric Surgery departments of Teaching Hospital of Bouaké. We included only patients from 0 to 15 years old who had digestive symptoms, an abdominal ultrasound scan. These patients were eligible for surgery. Data analysis was performed with Epi info 7 software. Results: Median age was 17.2 months [02 - 120]. Male gender predominated (83.3\%). Clinico-biological data were dominated by abdominal pain (79.2\%), vomiting (75\%) and rectorragies (33.3\%), with Ombredanne's triad in $33.3 \%$ and hyperleukocytosis (70.8\%). Ultrasonography showed invaginated coves (95.8\%) sitting in the right angl iliac fossa, peri-umbilical and right flank in $73.9 \%$. Cockade image coupled with the sandwich image accounted for 95.6\%. Superficial adenopathies (45.8\%) and peri-lesional fluid effusion (20.8\%) were associated with it. An occlusive syndrome complicating intus-
\end{abstract}


susception was observed in $41.67 \%$ associated with intra-peritoneal effusion of fluid (25\%). There was a significant diagnostic agreement between the clinic, ultrasound and surgery according to the Fisher's exact test $(p=0.002)$. That between ultrasound and surgery was calculated at $95.4 \%$. Conclusion: This study allowed us to show a good clinical-echo-surgical concordance. Ultrasound is therefore an undeniable diagnostic, prognostic and therapeutic tool in the exploration of intussusception, hence the interest of its prescription in the shortest possible time by the clinician.

\section{Keywords}

Ultrasound, Acute Intestinal Invagination, Child

\section{Introduction}

Acute intestinal invagination (A.I.I.) or intussuception is the penetration of an intestinal segment and its meso into the downstream intestine. It is the most common abdominal emergency in infants and young children, but can occur at any age. Intussuception is idiopathic in more than $95 \%$ of cases [1]. Its clinical manifestation is variable but classically includes paroxysmal abdominal pain, vomiting and bloody stools. Intestinal invagination results in intestinal occlusion and ischaemia with the risk of intestinal perforation and peritonitis [2] [3] [4]. Precarious financial situation of patients, but also the delay in diagnosis and treatment, puts their vital prognosis at risk. In our developing countries, A.I.I is characterized by a still very high morbidity and mortality [5]. This pathology therefore requires an abdominal ultrasound for its diagnosis. Ultrasound is the reference diagnostic examination. It allows us to determine anatomical type of the blood sausage, to identify digestive distress, to detect a primitive lesion and therefore to guide the therapeutic treatment [6]. Very few studies have been carried out on the contribution of ultrasound in management of this pathology. The objective of this study was to show relevance of ultrasound in the therapeutic management of a child's intussusception by correlating ultrasound diagnosis with the clinical and/or per operative diagnosis.

\section{Patients and Methods}

We carried out a retrospective study based on an exhaustive sampling. The study covered 24 files. This study was carried out in the Medical Imaging and Paediatric Surgery Departments of Teaching Hospital of Bouaké from July 2017 to September 2020. This hospital is only university hospital center in the interior of Côte d'Ivoire. Medical imaging department has standard and specialized radiography, ultrasound, mammography and dental panoramic units, as well as a scanner. However, there are 3 functionals units including ultrasound, standard radiography and specialize examinations with an estimated average of 30 and 60 examinations per day respectively. As for the paediatric surgery unit, it has 3 
beds and consults an average of 1700 children/year. These two services represent the reference services of the administrative region of Gbêkê. They cover a cosmopolitan and predominantly rural population estimated of projection from General Census of Population and Housing of 1998 in 2001 at 1,249,060 inhabitants [7].

Any child (0 - 15 years) suspected of A.I.I who had undergone an abdominal ultrasound and who was eligible for surgery with a usable medical record was selected for this study. We did not include newborns. Observations used as a basis for this work were reconstructed from:

- Medical records from the Paediatric Surgery Hospitalisation of Teaching Hospital of Bouaké,

- Radiological studies including ultrasound data of 24 infants and children who were referred to our Medical Imaging department for evaluation of a possible A.I.I.

- Registers of operative reports.

Variables studied were: age, sex, history of illness or surgery, results of physical examination, clinical diagnosis, results of haemogram as well as those of radiological examinations, modalities of surgical treatment.

Ultrasound scans were performed using 7.5 Mhz high-resolution linear transducers and low-frequency convex transducers (3.5 - $5 \mathrm{Mhz}$ ). If clinical conditions allow, for the ultrasound examination to be carried out, patient must fast for only 3 - 4 hours before examination. Patient should be supine, with the head resting on a small pillow, undressed to the waist. Ultrasound was considered positive in the presence of classic concentric ring or cockade image and sandwich image of intussuception in all patients suspected of A.I.I. This examination allowed the search for associated lesions and or complications such as state of abdominal solid organs notably liver, spleen, kidneys and pancreas, presence and location of intra-abdominal mass such as deep or superficial adenopathy, presence of fluid effusion as well as its abundance.

These patients were subsequently eligible for surgery. For patients who underwent surgery, a laparotomy was performed and a peroperative diagnosis was made, specifying appearance of invaginated loop, etiology or not and other findings as well as procedures performed. Data was analysed using Epi info version 7 software and figures were analysed using Microsoft Excel office 2013 software. Statistical analysis was initially descriptive, determining number of staff, calculating averages and comparing proportions, and then secondarily analytical using the exact Fisher test with $\alpha=0.05$ (significance threshold). Also for analytical study:

H0: $\mathrm{P}<0.05$; there is a link between variables studied;

$\mathrm{H} 1: \mathrm{P} \geq 0.05$; there is not link between variables studied.

Approval of the institutional ethics committee was obtained prior to the start of this study. There was no conflict of interest between the authors of this manuscript. 


\section{Results}

* Epidemiological aspects

Average age of the patients was 17.2 months with extremes of 2 and 120 months. Infants predominated in $83.3 \%$ of the cases in our study $(\mathrm{N}=20)$. These patients were not in school in 95.83\% $(\mathrm{N}=23)$ and their Expanded Programme on Immunization (E.P.I) and excluding EPI vaccination status was up to date in $83.3 \%$ and $16.7 \%$ respectively. Male gender represented $83.3 \%$ of the respondents, i.e. a sex ratio of 5 .

\section{Clinical and biological aspects}

Functional signs were dominated by classic symptomatic triad of Ombredanne (33.3\%), consisting of paroxysmal abdominal pain (79.2\%), bilious vomiting (75\%) and rectorragies (33.3\%).

Abdominal distension represented $41.67 \%(\mathrm{~N}=10)$ of functional signs presented by patients.

During physical examination, an oblong mass reflecting invagination sausage was palpable in $25 \%$ of cases $(\mathrm{N}=6)$, preferably palpated in right peri-umbilical region $(\mathrm{N}=3)$.

Dehydration and fever were the most common general signs in our study, reflecting poor general condition of patients in $58.3 \%(\mathrm{~N}=14)$ and $37.5 \%(\mathrm{~N}=9)$ of cases respectively.

Hyperleukocytosis $\left(\geq 11,000\right.$ elements $\left./ \mathrm{mm}^{3}\right)$ was associated with these clinical signs in $70.8 \%$ of cases $(\mathrm{N}=14)$.

\section{* Medical imaging aspects}

All patients had an abdominal ultrasound. However, no opaque enema was performed. Only $37.5 \%$ of patients had an x-ray of abdomen without preparation (ASP).

Concerning ultrasound aspects, invaginated intestinal loops were observed in $95.8 \%(\mathrm{~N}=23)$. These invaginated intestinal loops were preferentially on the right $(73.9 \%)$, particularly in right iliac fossa and right flank each in $26.1 \%(\mathrm{~N}=$ 6) and in peri-umbilical area in $21.7 \%(\mathrm{~N}=5)$.

Cockade image coupled with sandwich image (Figure 1) was the most represented with $95.6 \%(\mathrm{~N}=22)$. However, an indeterminate image was noted in $4.3 \%(\mathrm{~N}=1)$. In cross-section, diameter of cockade image varied between 20 $\mathrm{mm}$ and $50 \mathrm{~mm}$. Invagination sausage in cross-section measured between 30 and $50 \mathrm{~mm}$ in $81.8 \%$ of cases i.e. 18 cases (Table 1 ).

A.I.I was associated with intestinal occlusion in 10 patients (42\%), intraperitoneal fluid effusion in 6 patients (25\%) and intestinal ischaemia done to absence of vascular flow with colour Doppler in $34.8 \%(\mathrm{~N}=8)$ and peri-lesional fluid effusion (Figure 2), i.e. fluid trapped around the head of invagination coil in $20.8 \%(\mathrm{~N}=5)$. There were no cases of intestinal perforation.

These ultrasound signs were associated with superficial adenopathies (45\%) which were mostly located in mesentery (67\%).

All patients surveyed had integrity of solid intra-abdominal organs (liver, spleen, kidneys, pancreas). They had an alithiasic gallbladder with a thin wall. 


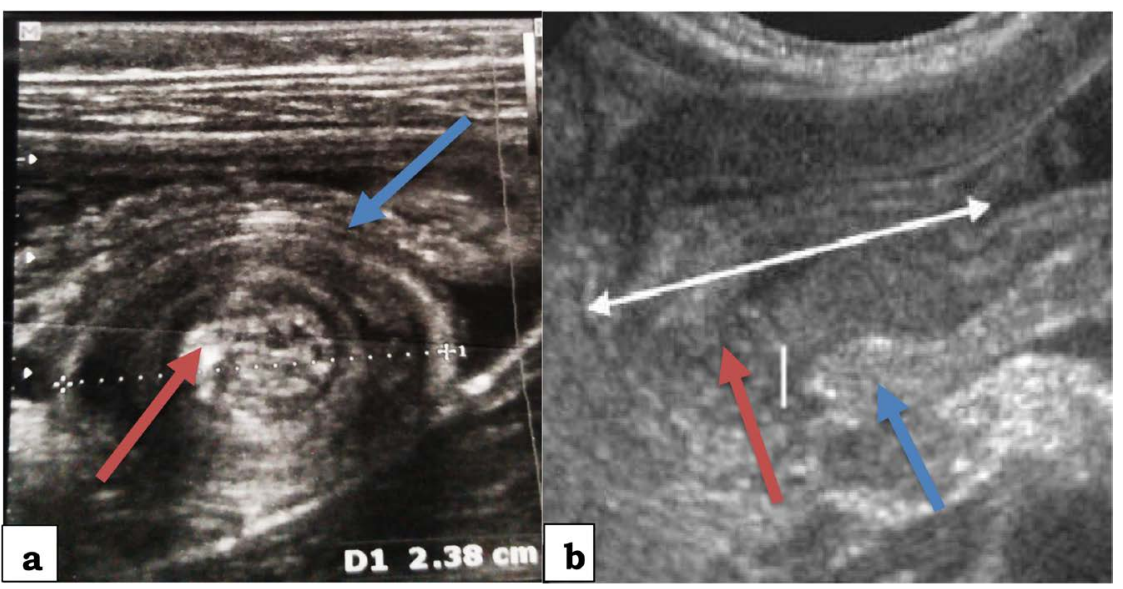

Figure 1. Cockade image (a) in cross-section and sandwich image, (b) in longitudinal section of an acute intestinal invagination showing invaginated loop (red arrow) and invaginating loop (blue arrow). (Photo library of the medical imaging department of Teaching Hospital of Bouaké).

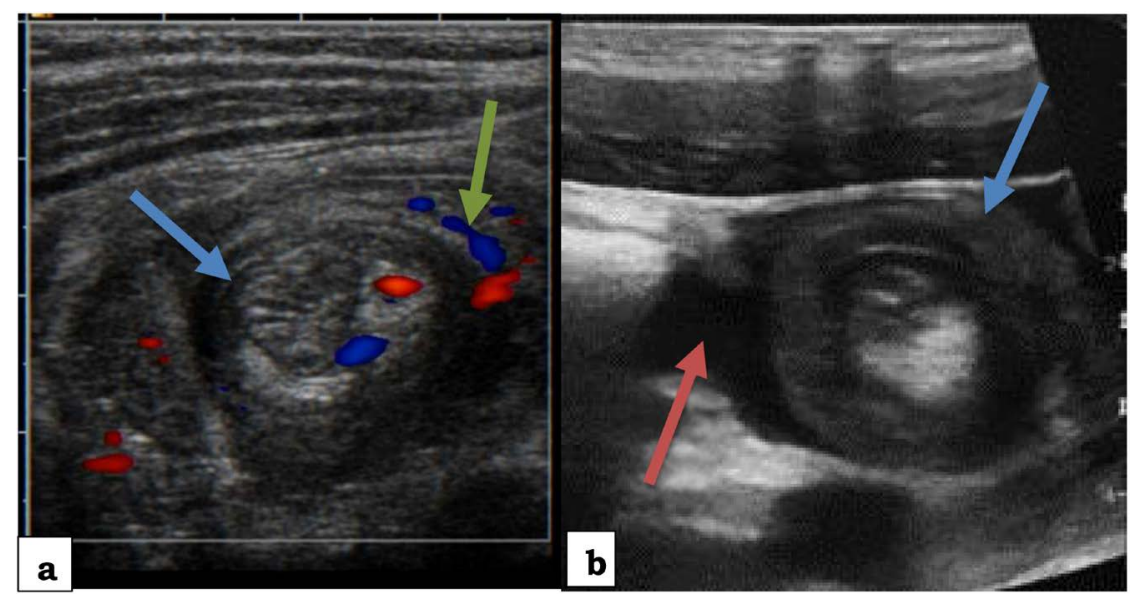

Figure 2. Cockade image (blue arrow) with colour Doppler signal (green arrow) and peri-leional fluid effusion (red arrow) on a cross-section. (Photograph from the radiology department of Teaching Hospital of Bouaké).

Table 1. Distribution of A.I.I. according to the diameter of the cockade image.

\begin{tabular}{ccc}
\hline Target image diameter $(\mathrm{mm})$ & $\mathrm{N}$ & $\%$ \\
\hline $20-30$ & 4 & 18.2 \\
$30-40$ & 14 & 63.6 \\
$40-50$ & 4 & 18.2 \\
Total & 22 & 100 \\
\hline
\end{tabular}

No other abdominal mass were found.

On the radiographic images of Abdomen Without Preparation (ASP), central hydro-aerial levels wider than high were found in $34.8 \%$ of cases $(\mathrm{N}=8)$. No opaque enema was performed in our study.

Diagnostic delay exceeded 48 hours in $79.2 \%$ of cases $(\mathrm{N}=19)$. 


\section{Intra-operative results}

Surgical confirmation of A.I.I. was effective in 22 patients, i.e. in $91.7 \%$ of cases (Figure 3).

Intestinal invagination was at the ileocolic level in $72.7 \%(\mathrm{~N}=16)$. Intestinal loops were viable in $63.6 \%(\mathrm{~N}=15)$ and necrotic in $31.8 \%(\mathrm{~N}=7)$.

Invagination's cause of these intestinal loops was not found in $81.8 \%(\mathrm{~N}=18)$. However, an ileal tumour was the etiology in $13.6 \%(\mathrm{~N}=3)$.

Mesenteric adenopathies were associated with A.I.I in $63.6 \%(\mathrm{~N}=14)$.

Surgical gesture performed were essentially manual desinvagination in $81.8 \%$ $(\mathrm{N}=18)$ and anastomosis resection in $31.8 \%(\mathrm{~N}=7)$.

\section{* Diagnostic concordance}

Positive predictive value (PPV) of ultrasound results concordant with surgery was calculated at $95.4 \%$. On the other hand, diagnostic concordance with the clinic was $47.6 \%$ (Table 2).

There is a significant diagnostic concordance between the clinic, ultrasound and surgery (Table 3 ).
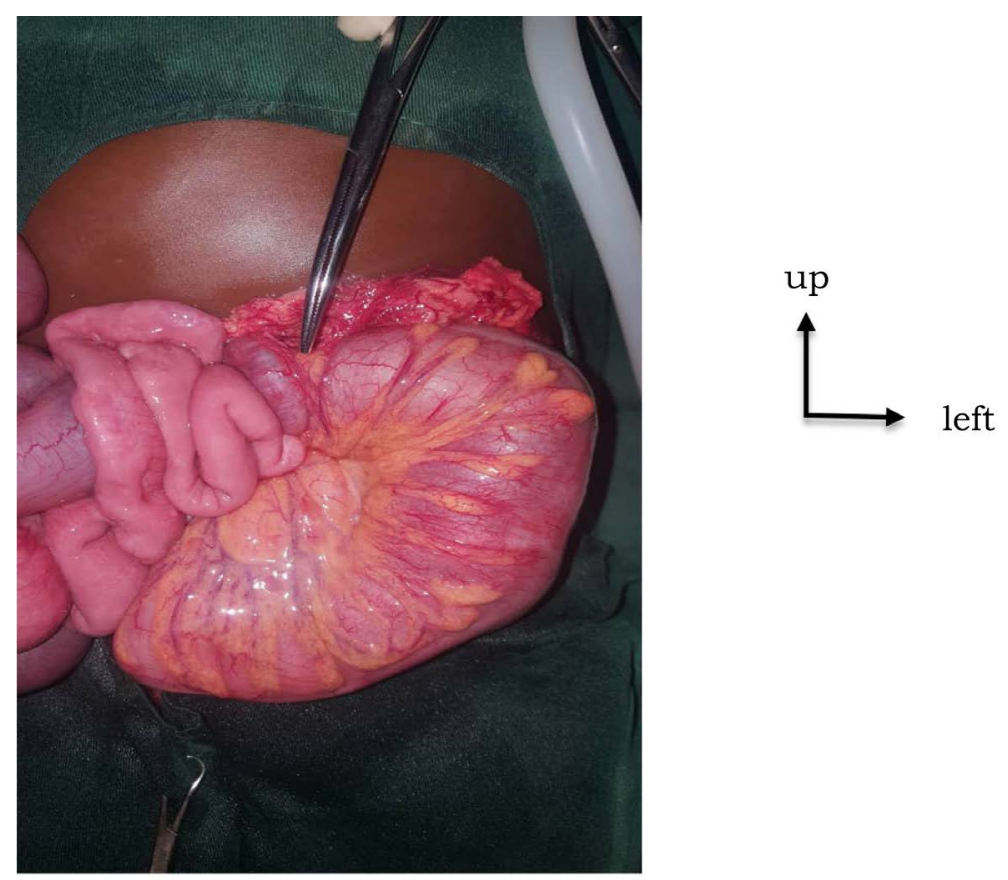

Figure 3. Intra-operative image showing a colo-colic invagination sausage. (Photo library of the paediatric surgery unit of Teaching Hospital of Bouaké).

Table 2. Clinical-echo-echo-surgical diagnostic concordance.

\begin{tabular}{cccc}
\hline Pathology & \multicolumn{3}{c}{ Diagnostic concordance } \\
\hline & Ultrasound scan & Clinic & PPV (\%) \\
A.I.I. & 21 & 10 & 47.6 \\
& Ultrasound scan & Surgery & PPV (\%) \\
& 21 & 22 & 95.4 \\
\hline
\end{tabular}


Table 3. Correlation between clinical diagnosis, ultrasound diagnosis and intraoperative diagnosis.

\begin{tabular}{ccccc}
\hline & Clinic & Ultrasound scan & Surgery & P \\
\hline Diagnostic concordance & $\mathrm{N}(\%)$ & $\mathrm{N}(\%)$ & $\mathrm{N}(\%)$ & \\
Yes & $10(45.5)$ & $21(95.4)$ & $22(100)$ & 0.002 \\
No & $12(54.5)$ & $1(4.6)$ & $0(0)$ & \\
\hline
\end{tabular}

Evolution of our patients was marked by one case of spontaneous disinvagination confirmed by ultrasound. We therefore had 23 patients eligible for surgery. However, we recorded one death during intra-operative resuscitation during induction of anaesthetic product. Surgical confirmation of the A.I.I was therefore effective in 22 patients. Operative consequences in these patients were simple.

\section{Limits}

The aim of this study was to show relevance of ultrasound in therapeutic management of the child's intussusception by correlating diagnostic-echo with clinical and/or per operative diagnosis. However, relatively small number of cases represented a limitation in this study. This limited number can be explained by the large number of people lost to the precarious socio-economic conditions of population.

\section{Discussion}

\section{* Epidemiological aspects}

Average age of patients was 17.2 months. Infants were the most represented among patients in $85 \%$ of cases. These results are consistent with those of Rakotoarisoa [8] who found a predominance of infants in her study but with a younger average age of 8.1 months.

Male sex observed in this study is consistent with data in literature [8] [9] [10] [11]. According to Weihmiller, male sex is a factor favouring acute intestinal invagination and accounts for $60 \%$ of cases [12].

\section{* Clinical aspects}

Diagnosis time exceeded 48 hours in $79.2 \%$ of cases. Carcassonne [13] and Rakotoarisoa [8] reported average durations of 35.5 hours and 44.1 hours respectively, with extremes of 6 hours to 5 days in their studies. This delay in diagnosis is said to result from unfavourable socio-cultural and economic conditions of our populations who first try traditional medication for digestive disorders before considering a medical consultation. Also, absence of social security in our health centers is a hindrance to early diagnosis of patients. There is also a lack of awareness of this pathology among both para-medical and non-specialised medical staff. The time required to diagnose an A.I.I. is highly dependent on the skills of practitioner and available equipment [14].

Beyond a positive diagnosis, the clinical examination aims to assess severity of 
A.I.I. and thus guide chronology of further examinations and treatment. A.I.I. has a clinical polymorphism however it is very often evoked in front of Kirmisson Ombredanne's classic symptomatic triad made of paroxysmal abdominal pain, bilious vomiting and rectorragies associated or not with the perception of an invagination sausage.

In our study, this triad dominated the functional signs with $33.3 \%$. This rate is higher than that of Vandertuin, who noted presence of this triad in $24 \%$ of patients (7 out of 29) in Geneva and only in 1 case out of 37 in Lausanne [15]. For Bines, only $20 \%$ of invaginations have such a presentation [16], because in current practice it is difficult to observe these three signs at same time.

Invagination sausage was palpable in 6 patients, i.e. $25 \%$. This rate is close to that of Rakotoarisoa [8] who found an abdominal mass 7 times out of 22, i.e. in $31.8 \%$ of cases. These data are comparable to those in literature, which found invagination sausage's head in $25 \%$ to $50 \%$ of ileocolic invaginations [16].

\section{* Medical imaging aspects}

Invaginated loops were observed in almost all cases, 95.8\% $(\mathrm{N}=23)$. Cockade image was represented in $95.6 \%$ of cases. According to Vandertuin [15], this image, which corresponds in cross-section to the layers of intestinal walls inside each other, is easily identifiable. Abdominal ultrasound by an experienced radiologist is currently examination of choice to confirm diagnosis of an intestinal invagination. Sensitivity and specificity of this examination is close to $100 \%$ [17].

Right location of invagination sausage was the most represented (73.9\%), consisting of right iliac fossa and right flank involvement in $26.1 \%$ each and peri-umbilical involvement (21.7\%). This result is close to the data in literature, particularly in Franchi's study [18], in which the vast majority of intestinal invaginations occurred in right subhepatic region and on right flank. This right location of A.I.I. is inherent to high frequency of ileocolic topography [1]. However, all areas of abdomen must be explored, as the head of invagination sausage may sit as far as the rectum.

In $73.7 \%$ of cases, invagination sausages measured more than $30 \mathrm{~mm}$ in cross-section diameter. According to literature, this indicates an ileocolic or colocolic invagination [18]. Our result is therefore consistent with those of De Lamber and Franchi, who found that an ileocolic or colocolic invagination coil in cross-section measures between 30 and $50 \mathrm{~mm}$ in diameter and is located under the abdominal wall [18] [19].

\section{* Therapeutic aspects}

From a therapeutic point of view, many recent publications confirm interest of barium enema in reducing A.I.I. of infants [19] [20]. According to Becmeur [21], before deciding on a non-operative treatment, it is necessary to ensure its safety and assess its chances of success. None of our patients have been able to benefit from this so-called medical reduction treatment for clinical and technical reasons. In our practice, surgery unfortunately still remains the only logical therapeutic weapon. Twenty-two patients or $91.7 \%$ were treated surgically in our 
study. The poor general condition of patients, clinical and ultrasound signs of seriousness but above all diagnostic delay which exceeded 48 hours in the majority of cases justified this surgical indication in these 22 patients. Major ultrasound criteria for the seriousness of an A.I.I. are hail signalling an obstruction and presence of liquid trapped around the head of invagination sausage showing digestive suffering. We detected 5 cases, i.e. $20.8 \%$ in our study. The greater the quantity of liquid, the greater the degree of suffering [22]. According to Baud, combination of two severity criteria leads to surgical treatment [5].

As for the site of lesion, it was an ileocolic A.I.I. in majority of patients (77.8\%). Our ultrasound results and data from literature are close to this result [1] [15].

Invagination's cause of these coves was not found in $81.8 \%(\mathrm{~N}=18)$, which is evidence of idiopathic etiology well described in literature related to intusception [1]. Ileal tumour $(\mathrm{N}=3)$ and dolichocolon $(\mathrm{N}=1)$ were only etiologies observed in our study.

\section{* Diagnostic concordance}

We assessed the diagnostic concordance on 22 files in this study. There was indeed a significant concordance between clinical, ultrasound and per operative diagnosis $(\mathrm{p}=0.002<0.05)$. Clinical-echo diagnostic concordance (PPV) was calculated at $47.6 \%$, thus reflecting a high diagnostic discordance (Table 2). This discrepancy could be explained by difficulty in obtaining symptomatic triad in clinical picture and also in palpating invagination sausage.

Relevance of ultrasound results was therefore assessed after laparotomy. This enabled us to calculate positive predictive value (PPV) of ultrasound results which was very high: $95.4 \%$. This result is in agreement with that of other authors who agree on primordial importance of ultrasound in diagnosis of A.I.I. in children. Kouamé [23] found a positive predictive value of $100 \%$.

\section{Conclusion}

In spite of the poverty of technical platform, ultrasound in sub-Saharan Africa remains essential in the care of children with A.I.I. In this study, it allowed us to make a positive diagnosis with a very high positive predictive value (95.4\%). We evaluated clinical-echo-surgical diagnostic concordance which was significant ( $\mathrm{p}$ $=0.002)$. In order to reduce morbi-mortality linked to A.I.I, it is necessary to raise awareness and increase knowledge of practitioners, and to promote multidisciplinary consultation meetings involving radiologists and paediatric surgeons. A study on desinvagination by water enema under ultrasound surveillance could be envisaged to reduce the occurrence of complications, thus contributing to early diagnosis and treatment.

\section{Conflicts of Interest}

The authors declare no conflicts of interest regarding the publication of this paper. 


\section{References}

[1] Baud, C., Prodhomme, O., Forgues, D., Saguintaah, M., Veyrac, C. and Couture, A. (2012) Acute Intestinal Invagination of Infants and Children. Radiology and Abdominal Digestive Medical Imaging. Elsevier Masson SAS, Paris, 1-19.

[2] Soyun, H., Joonghee, K., Jae, Y.J., Eun, M.H., Joong, W.P., Hyuksool, K., Do, K.K. and Young, H.K. (2019) The Epidemiology of Childhood Intussusception in South Korea: An Observational Study. PLoS ONE, 14, e0219286. https://doi.org/10.1371/journal.pone.0219286

[3] Emily, A.E., Nicholas, P., Jesse, C., Matthew, A.Z., John, D.M. and Andrew, S.P. (2017) Intussusception: Past, Present and Future. Pediatric Radiology, 47, 1101-1108. https://doi.org/10.1007/s00247-017-3878-x

[4] Bines, J.E., Ivanoff, B., Justice, F. and Mulholland, K. (2004) Clinical Case Definition for the Diagnosis of Acute Intussusception. Journal of Pediatric Gastroenterology and Nutrition, 39, 11-18. https://doi.org/10.1097/00005176-200411000-00012

[5] Gnassingbé, K., Abarchi, H., Akakpo-Numado, G.K., Attipou, K. and Tékou, H. (2004) Problems Caused by Acute Intestinal Invaginations in Infants at Tokoin University Hospital in Lomé: About 37 Cases. African Journal of Digestive Surgery, 4, 333-337.

[6] Baud, C., Taleb-Arrada, I., Eulliot, J., Sevette-Bechard, N., David, S., Saguintaah, M., et al. (2019) Ultrasound Diagnosis of Acute Intestinal Invagination in Children and Therapeutic Impact. Journal of Diagnostic and Interventional Imaging, 2, 135-142. https://doi.org/10.1016/j.jidi.2019.03.004

[7] Institut National de Statistique (1998) General Census of Population and Housing (RGHP)—Côte d'Ivoire.

[8] Rakotoarisoa, B., Rabarijaona, M., Zafitasondry, Rabarioelina, L. and Andrianandrasana, A. (2001) Invagination intestinale aigüe du nourrisson: A propos de 22 cas traités chirurgicalement dans le service de chirurgie pédiatrique au CHU d'Antananarivo. Black African Medicine, 48, 358-362.

[9] Harouna, Y., Tardivel, G., Abdou, J. and Gamatie, Y. (1997) Prognosis of Acute Intestinal Invagination in Infants at Niamey Hospital. Bulletin de la Societe de Pathologie Exotique, 90, 30-32.

[10] Heraldot, P., et al. (1986) Acute Intestinal Invagination of the Infant. EMC, Paris. EMC Gastro-Enterology, 2, 362.

[11] Giraud, J. (1980) Acute Intestinal Invagination of the Infant. LMM South-East Med, 16, 3128-3131.

[12] Weihmiller, S.N., Monuteaux, M.C. and Bachur, R.G. (2012) Ability of Pediatric Physicians to Judge the Likelihood of Intussusception. Pediatric Emergency Care, 28, 136-140. https://doi.org/10.1097/PEC.0b013e3182442db1

[13] Carcassonne, M., Roffe, J. and Bonnet, G. (1977) Acute Intestinal Invagination of the Infant: Analysis of a Statistic. Annals of Surgery, 18, 453-475.

[14] Renat, L., Rajabboy, K. and Elmira, F. (2011) Childhood Intussusception in Uzbekistan: Analysis of Retrospective Surveillance Data. BMC Pediatrics, 11, Article No. 22. https://doi.org/10.1186/1471-2431-11-22

[15] Vandertuin, L., Vunda, A., Gehri, M., Sanchez, O., Hanquinet, S. and Gervaix, A. (2011) Intestinal Invagination in Children: A Truly Classic Triad? Revue Médicale Suisse, 7, 451-455.

[16] Bines, J. and Ivanoff, B. (2002) Acute Intussusception in Infants and Children. Incidence, Clinical Presentation and Management: A Global Perspective. World Health 
Organisation Vaccines and Biologicals.

[17] Hanquinet, S., Anooshiravani, M., Vunda, A., Le Coultre, C. and Bugmann, P. (1998) Reliability of Color Doppler and Power Doppler Sonography in the Evaluation of Intussuscepted Bowel Viability. Pediatric Surgery International, 13, 360-362. https://doi.org/10.1007/s003830050339

[18] Franchi, S., Martelli, H., Paye-Jaouen, A., Goldszmidt, D. and Pariente, D. (2005) Acute Intestinal Intussusception in Infants and Children. EMC-Pediatrics, 2, 45-57. https://doi.org/10.1016/j.emcped.2004.11.001

[19] De Lamber, G., Guerin, F., Franchi-Abella, S., Boubnova, J. and Martelli, H. (2015) Acute Intestinal Intussusception in Infants and Children. EMC Journal of Paediatrics and Child Care, 28, 1-13.

[20] Wild, P. (1995) Acute Intestinal Invagination of the Infant: Physiopathology, Diagnosis, Evolution, Prognosis, Treatment. La Revue du Praticien, 45, 225-230.

[21] Becmeur, F., Christmann, D. and Bosser, V. (1994) Intestinal Invagination of the Infant: An Infant Surgery Emergency Still in the News. Journal de Medecine de Strasbourg, 25, 54-56.

[22] Del-Pozo, G., Gonzales-Spinola, M.B., Gomez-Anson, B., Serrano, C., Mirailles, M., Gonzales DeOrbe, G., et al. (1996) Intussusception: Trapped Peritoneal Fluid Detected with US-Relationship to Reducibility and Ischemia. Radiology, 201, 379-383. https://doi.org/10.1148/radiology.201.2.8888227

[23] Kouamé, N., Dieth, A., Soumma, A., Manewa, F., Ngoan-Domoua, A. and N'Gbesso, R. (2017) Management of Acute Non-Traumatic Abdominal Pain in Children in Abidjan: Is the Standard Radiography/Ultrasound Pair Still Topical? African Journal of Medical Imaging, 9, 17-20. 